\title{
Encouraging the Innovative Use of Geometer's Sketchpad through Lesson Study
}

\author{
Chew Cheng Meng, Lim Chap Sam \\ Universiti Sains Malaysia, Penang, Malaysia. \\ Email: cmchew@usm.my,cslim@usm.my \\ Received March 10 $0^{\text {th }}, 2011$; revised April 8 ${ }^{\text {th }}$, 2011; accepted April 20 2011.
}

\begin{abstract}
The purpose of this study was to encourage the innovative use of Geometer's Sketchpad (GSP) in the teaching and learning of mathematics among secondary school teachers in Malaysia through Lesson Study (LS). Three LS groups were set up in three secondary schools. Qualitative data were collected through written lesson plans, video-taped teaching and individual interviews with the participants. Findings of the study show positive changes in the participants' knowledge and skills of using GSP to teach the topics of "Lines and Planes in Three Dimensions," "Loci in Two Dimensions" and "Plans and Elevations." These are evidenced in their mathematics lesson plans, GSP sketches, worksheets and videotaped teaching observations. Analysis of their interview transcripts also reveals positive acceptance and encouraging feedback about LS that promotes peer support and collaboration. Thus, the participants have more confidence in using GSP innovatively to teach mathematics at the secondary school level after the LS collaboration.
\end{abstract}

Keywords: Lesson Study, Geometer’s Sketchpad, Mathematics Teaching and Learning, Secondary School

\section{Introduction}

The purpose of this study was to encourage the innovative use of Geometer's Sketchpad (GSP) in the teaching and learning of mathematics among secondary school teachers in Malaysia through Lesson Study (LS). We will begin this paper by discussing the importance of GSP in the teaching and learning of mathematics in general and geometry in particular. This is followed by discussing the significance of LS as a potential model of teacher professional development in schools and as a potential driving force for encouraging the innovative use of GSP in the teaching and learning of mathematics among secondary school teachers.

\section{Importance of GSP}

GSP is a dynamic geometry software program for constructing and investigating mathematical objects. It is a dynamic tool for construction, demonstration and exploration that adds a powerful dimension to the learning of geometry and many other areas of mathematics. Further, research has shown that GSP can be an innovative tool for enhancing students' learning of plane geometry (Choi, 1996; Choi-Koh, 1999; Choi-Koh \& Sang Sook, 2000; Driskell, 2004; Elchuck, 1992; Frerking, 1995; Hannafin, Burruss, \& Little, 2001; Abdullah, 2005; Thompson, 2006) and solid geometry as well (Chew, 2007; July, 2001; McClintock, Jiang \& July, 2002).

However, in Malaysian classrooms, the use of GSP in the teaching and learning of mathematics is still very much at its infancy state even though the Malaysian Ministry of Education has purchased the GSP license and supplied the GSP software to all secondary schools in Malaysia since 2004. While it is envisaged that this initiative will benefit many teachers and students as well as teacher educators nationwide, teacher enthusiasm and willingness to use GSP remains an issue to be ad- dressed (Teoh \& Fong, 2005). In fact, a study conducted by Kasmawati (2006) on 151 teachers around Penang state showed that $26 \%$ of the mathematics teachers had gone for the GSP training courses but only $2 \%$ of them used GSP to teach mathematics in their classes. Two major reasons given by these teachers were 1) lack of time to prepare a GSP lesson and 2) lack of skills and confidence to use GSP to teach mathematics in class. Hence, there is an urgent need to set up a collaborative group effort such as lesson study groups in schools that will provide helpful support as well as sustain the continuous and innovative use of GSP in secondary school mathematics teaching.

\section{Significance of LS}

LS is a form of teacher professional development practised decades ago in Japan. From the literature, LS was well established since the 1960s (Fernandez \& Yoshida, 2004) but claims were also made that LS had actually started in the late 19th century (Isoda, Stephens, Ohara, \& Miyakawa, 2007). LS is a process whereby small groups of teachers (usually 4 or 5 teachers) meet at stipulated time to plan, implement, evaluate, and revise lesson plan collaboratively. It is initiated and organised by the teachers themselves as study groups at school or district level with the aim to improve their teaching competency. The main purpose of LS is to enhance teachers' pedagogical knowledge and skills through peers' review, critique and collaboration among teachers (Shimahara, 1998). It is an on-going practice in Japan as a form of teacher professional development especially in elementary schools. In Japanese teaching career, teachers would engage in a relentless and continuous process of improving their teaching by participation in lesson study groups (Stigler \& Hiebert, 1997; Shimahara, 1998; Lewis \& Tsuchida 1998; Stigler \& Hiebert, 1999; Yoshida, 1999; Lewis, 2000). As a result, Japanese teachers have well adapted LS as part of 
their teaching career and profession. It is the teacher-initiated and self-directed form of teacher professional development that makes it a unique type of in-service practice in the teaching profession. In fact, LS is now practised in many other countries all over the world (Isoda et al., 2007).

Basically, according to Fernandez and Yoshida (2004: pp. 7-9), a LS cycle consists of the following 6 steps:

\section{Step 1: Collaboratively Planning the Lesson Plan}

Teachers come together to plan the lesson in collaborative nature. They share their teaching knowledge and ideas on how to design a good lesson drawing on their past experiences, observations on students' abilities and ideas from resources and textbooks. The end product is a lesson plan that describes in details the process of teaching and learning.

\section{Step 2: Seeing the Lesson Plan in Action}

A teacher from the group will implement the lesson plan to his or her students. Other teachers will act as observers during the lesson. Occasionally, an expert from an educational institution is invited to observe the lesson.

\section{Step 3: Discussing the Lesson Plan}

The teachers will then come together to reflect on the lesson that has been taught in a real classroom context. The teachers share what they have observed during the lesson and comment on their reflections as well as provide suggestions.

\section{Step 4: Revising the Lesson Plan}

Based on the teachers' observations and reflections of the lesson, the teachers will decide collaboratively to revise and update a new version of the lesson plan.

\section{Step 5: Teaching the New Version of the Lesson}

Although this step is optional, very often another teacher from the group will teach the revised version of the lesson in another classroom. As in the previous observed lesson, other teachers will again act as observers during the lesson.

\section{Step 6: Sharing Reflections about the New Version of the Lesson}

The teachers will come together again to discuss and reflect on the revised version of the lesson taught. Again, the teachers share their observations, comments and suggestions. Following this, they collaboratively revise the lesson plan.

In fact, a substantial amount of research studies (see Stigler \& Hiebert, 1997; Shimahara, 1998; Lewis \& Tsuchida, 1998; Stigler \& Hiebert, 1999; Yoshida, 1999; Lewis, 2000; Fernandez, \& Yoshida, 2004) have shown that LS improves teachers' learning and supports teachers to grow professionally. However, to date, no related research has yet been found to encourage the innovative use of GSP in the teaching and learning of mathematics among secondary school teachers in Malaysia through LS. Therefore, this has spurred our motivation and interest to adopt LS as a means to encourage the innovative use of GSP among secondary school mathematics teachers in Malaysia.

\section{Purpose of the Study}

The purpose of this study was to encourage the innovative use of GSP in the teaching and learning of mathematics among secondary school teachers in Malaysia through LS. More specifically, this paper discusses the extent to which LS encour- aged the innovative use of GSP in the teaching and learning of mathematics among secondary school teachers in Malaysia.

\section{Method}

LS is a teacher-led professional development and thus voluntary participation from the teachers is an essential factor in ensuring its success. We began by approaching dedicated and voluntary mathematics teachers from different schools in the states of Penang and Kedah to be recruited as participants. They were then asked to seek three to five mathematics teachers from their respective schools to form a LS group. Upon their consent, we sought permission from their respective school administrators to recruit the teachers as participants. Finally, three LS groups were set up in three secondary schools, two in the state of Penang and one in the state of Kedah. The two secondary schools in Penang were named School A and School B while the secondary school in Kedah was named School C. Schools A and $\mathrm{C}$ are ordinary public secondary schools located in the mainland of Penang and Kedah respectively. School A had 120 teachers and about 2300 students whereas School C had 77 teachers and about 1000 students including 40 special need students (deaf and mute) at that time. School B is a secondary boarding school located in the mainland of Penang with 70 teachers and about 670 students. All the selected students for admission to School B were above average achievers.

To begin, all the participants attended a one-day workshop on GSP conducted by an expert in GSP. The aim was to expose and enhance the participants' knowledge and skills in GSP. They were also briefly introduced to the concept and process of LS as well as the research procedure. Data were collected using questionnaire to gauge the participants' knowledge, skills, perceptions and practices of GSP in the teaching and learning of mathematics.

After the one-day workshop, all the participating schools began their LS cycle individually from July 2007 till May 2008. At the end of the project, even though each school managed to implement at least two LS cycles, the degree of success in encouraging the innovative use of GSP in the teaching and learning of mathematics in each school varied. This is because each of the LS groups encountered different constraints and challenges in implementing the study. For each case, qualitative data were collected through written lesson plans, GSP sketches, worksheets, video-taped teaching and discussions as well as teachers' and students' interviews.

\section{Findings and Discussion}

In this section, the findings of the extent to which LS encouraged the innovative use of GSP in the teaching and learning of mathematics among secondary school teachers in the three LS groups are discussed. For easy reference, the LS groups in Schools A, B and C were named Groups A, B and C respectively.

\section{Group A}

Group A consisted of four mathematics teachers. All of them majored in mathematics and have more than ten years of mathematics teaching experience. GSI is the Senior Teacher of Science and Mathematics in the school and thus was the LS 
group leader. Among the participants, GSI has fairly good knowledge and skills of using GSP as she had previously attended two GSP related workshops organised by the Penang State Education Department. Her background knowledge and skills in GSP has certainly rendered her an advantage in facilitating and leading her LS group members who were novice users of GSP.

The group had completed two LS cycles. During this period, the group members met at stipulated times after school dismissal to engage in the LS cycles. Some of the sessions were also held during weekends and public holidays. Although partly due to the busy work schedule of teachers during week days, the willingness of teachers to sacrifice their weekends and holidays to learn and practise GSP is clearly an encouraging reflection of the positive attitudes of these teachers towards the LS collaboration.

In the first LS cycle, the group members selected a topic in one of the Form 4 (the fourth year of Malaysian secondary education) Mathematics chapters, namely Lines and Planes in 3-Dimensions (3-D). The topic briefly introduces lines and planes in 3-D and students are then required to identify and calculate: 1) the angle between two lines, 2) the angle between a line and a plane, and 3) the angle between two planes. Based on their teaching experiences, students generally have difficulties in identifying and calculating the required angles. Thus they believed that by using GSP, students might be able to visualise and identify the required angles through the direct manipulation of the 3-D objects on the computer screen.

Three LS discussions were held to plan the lesson prior to the teaching of the topic. During the discussions, GSI discovered that her group members were struggling to learn how to construct 3-D objects in GSP. Thus, she offered herself to assist them in the construction of the 3-D objects in GSP whenever possible as comparatively she has more knowledge and experience in GSP. In fact, GSI took the role as the leader and facilitator of the group in every discussion session and she found that the interactions with the group members were worthwhile experiences. After the lesson plan was finalised, GSI volunteered to teach the collaboratively planned lesson in one Form 4 class in the computer laboratory of the school. The teaching was observed by all members as well as the second author who played the role as both a researcher and an external advisor.

An analysis of the lesson plan, GSP sketches, worksheets and videotaped teaching observation did illuminate GSI's ability to use GSP sketches to teach the topic. For example, the lesson began with a brief explanation of the content and concepts of Lines and Planes in Three Dimensions by GSI. She then used the "animated program" as in Figures 1 and 2 for exposition. The students had the options of selecting the objects in GSP and they could adjust and rotate the solids by clicking on the respective buttons so that they could visualize the angles between lines and planes as well as the angles between two planes from different perspectives.

Immediately after the teaching, a reflection session of the lesson was held. The group members reflected that GSP was effective in enhancing the students' conceptual understanding of the 3-D objects. Since all the group members were satisfied with the lesson, no revision was made to the lesson plan. Although they planned to re-teach the same lesson in another class, unfortunately it was not implemented as no group member was

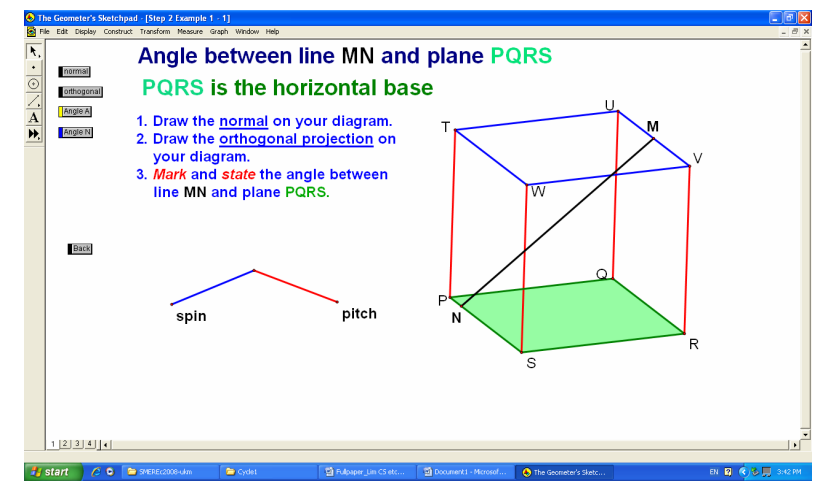

Figure 1.

A GSP sketch of a cube.

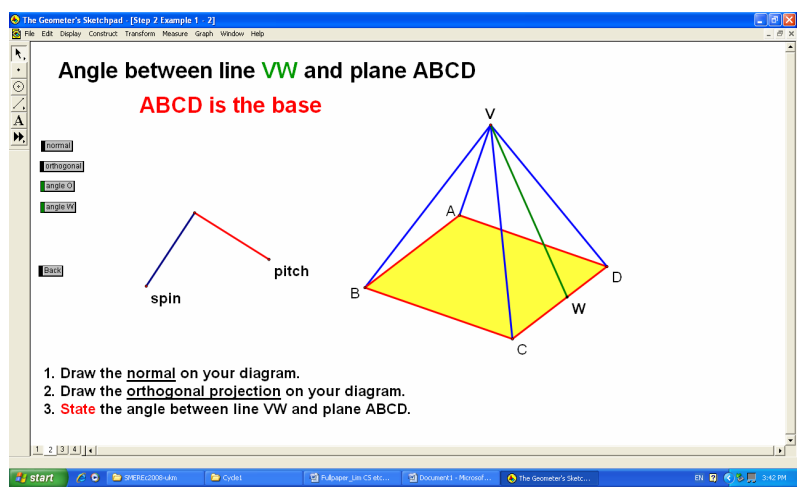

Figure 2.

A GSP sketch of a pyramid.

willing to have his/her teaching being videotaped and observed (Goh, 2010).

But, in the second LS cycle, the group members collaboratively decided to use GSP merely for revising one of the mathematics topics that was difficult for the Form 3 students. Based on their experiences in the first LS cycle, they felt the constraint to gather the participants for teaching observation at a particular time. Hence, they chose a topic in one of the Form 2 Mathematics chapters, namely Loci in 2-Dimensions (2-D) but planned to teach the lesson to the Form 3 students. Another main reason was that they felt the use of GSP was appropriate and suitable for teaching the topic as it could help students to visualise the movement of a point in 2-D through the animation of the movement of the point. The content of the topic briefly is about a moving point in equal distance from: 1) a fixed point, 2) two fixed points, 3) a straight line, and 4) two straight lines.

Three LS discussion sessions which include planning of lesson plan and hands-on practices with GSP were conducted prior to the teaching. During the discussions, the group members collaboratively constructed GSP sketches to be used in teaching the topic. Once again, GSI facilitated the three discussion sessions. A group member volunteered to conduct the first teaching using one Form 3 class in the computer laboratory as the students needed to use computers in their group activities. The lesson also began with a brief explanation of the content and concepts of Loci in Two Dimensions by the teacher. Then, the teacher employed the "animated program" as in Figures 3 and 4 for exposition. The students had the options of selecting the 


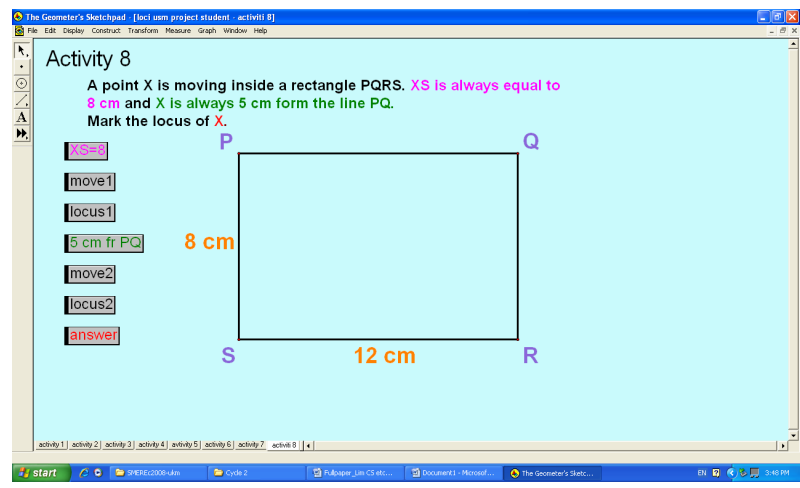

Figure 3.

A GSP sketch of a rectangle.

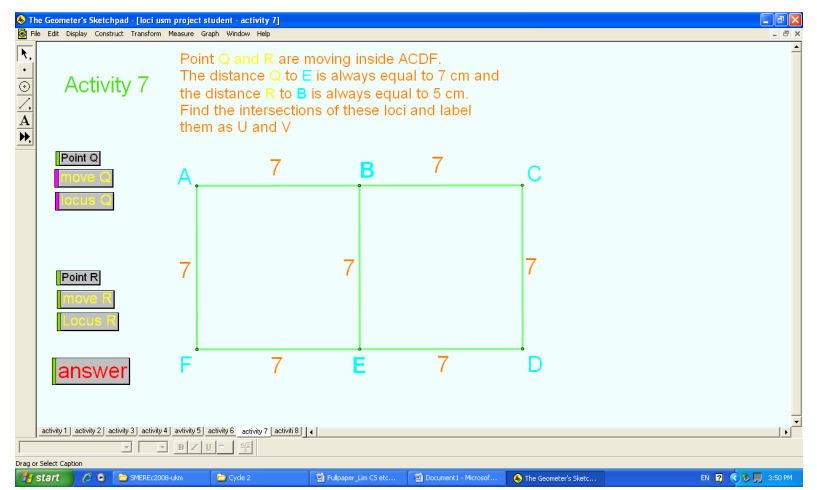

Figure 4.

A GSP sketch of a problem involving loci in $2 D$.

objects in GSP and they could display the loci of the points by clicking on the respective buttons.

As in the first LS cycle, a reflection session was held immediately after the observed lesson. During the reflection of the first teaching, the teacher pointed out that the students were too eager to explore the GSP sketches by clicking the action buttons for the succeeding steps instead of listening to the teacher's instructions. Consequently, some of the students could not follow the instructions half way through the lesson. To solve this problem, they suggested that the students ought to try the questions on their own first before checking their answers provided in the GSP sketches.

Based on the suggestion, another group member agreed to conduct the second teaching using another Form 3 class in the computer laboratory as the students also needed to use computers in their group activities. The implementation of this suggestion had made the second teaching to be conducted more systematically by the second teacher. Nevertheless, they observed that all the students were motivated and actively engaged in the lesson. They acknowledged that the students were excited with the lesson using GSP.

It was evident from the written lesson plans that the participating teachers have attempted to make full use of GSP features such as animation and dynamic capabilities to enable their students to acquire better understanding of the geometrical concepts. Another notable observation was that these teachers had designed in the lessons, especially for the topic of "Loci in Two Dimensions", questions that were similar to those in public examination. These questions and diagrams were collaboratively prepared by the participants through the LS collaboration. Although this was not the explicit goal in the LS collaboration, this adaptation was positively received by both the teachers and students. Any approaches that enhance students' achievement in public examination are always welcome by all parties in this examination-oriented culture of Malaysian society.

\section{Group B}

Group B also consisted of four mathematics teachers. All of them majored in mathematics and have more than ten years of mathematics teaching experience. TKA is the Excellent Mathematics teacher (that is, a title accorded by the Ministry of Education to a teacher who is expert in his subject area and excels in his teaching practice) in the school and thus was the LS group leader. Among the participants, TKA has fairly good knowledge and skills in GSP and this has also certainly rendered him an advantage in facilitating and leading his LS group members who were novice users of GSP.

In the first LS cycle, Group B members also selected a similar topic in one of the Form 4 Mathematics chapters, namely Lines and Planes in 3-Dimensions (3-D). But, in the second LS cycle, the group members chose a topic in one of the Form 5 Mathematics chapters, namely Plans and Elevations because they felt that this topic often causes much confusion among students especially in visualizing the real object in its actual perspectives. During the first teaching of the second LS cycle, one of the group members volunteered to teach the topic. First, he used GSP to demonstrate how 3-D objects could be rotated to show their plans and elevations. Then, the students were given 25 minutes to sketch the plan and elevations of the 3-D objects shown on the screen. Finally, the teacher showed the plans and elevations of the 3-D objects on the screen by rotating the 3-D objects in GSP for the students to check their answers. During the reflection session of the lesson, some group members felt that the learning process was too teacher-centered and monotonous. A member suggested that a more studentcentered approach ought to be used in line with the LS goal. He felt that the students would be more engaged in the learning process if they themselves were to use GSP to find the plans and elevations of the 3-D objects. However, other members were sceptical about the students' ability to use GSP. Finally, the group members came to a consensus that they would give the students a training session to learn some basic skills of constructing 3-D objects using GSP prior to the second teaching of the lesson.

During the second teaching of the lesson, the students were given hand-outs containing figures of $3-\mathrm{D}$ objects (see Figure 5).

The instructions for completing the task in Figure 5 are as follows:

Look at the solid in the diagram. Sketch on the paper provided,

1) the plan of the solid

2) the elevation of the solid as viewed from $X$

3) the elevation of the solid as viewed from $Y$.

After you have completed your drawings, compare your pictures with your friends beside you.

Now, draw the solid in your computer using the template provided. 


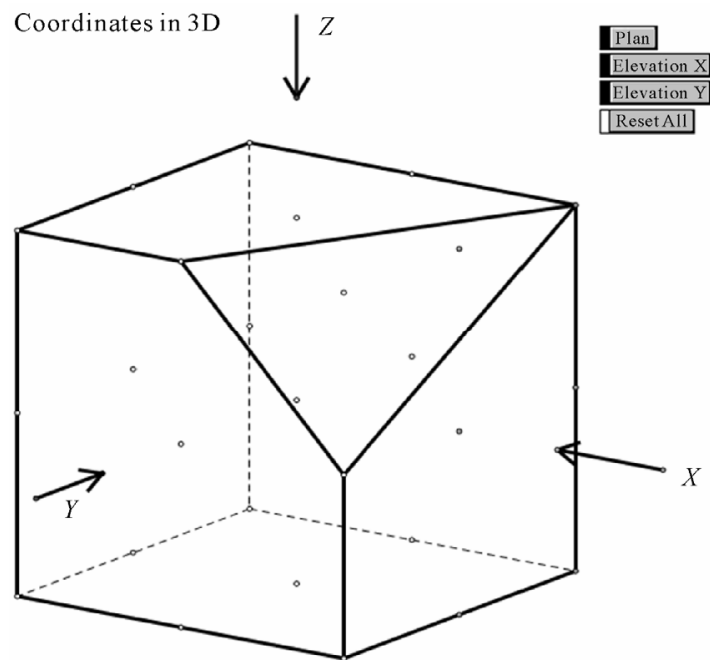

Figure 5.

An example of the task given in the second teaching of the lesson. Source: Tan (2010: p. 36).

After you have completed your drawing, rotate the solid in your computer so as to view it from the direction of $Z, X$ and $Y$ respectively.

Check to see if you have drawn your plan and elevations correctly.

Discuss your answers with your friends beside you.

Besides sketching the plan and elevation of the 3-D object given on the paper, the students were required to rotate the object on the GSP screen to verify their answers. This time, the students were rather engrossed in directly manipulating the 3-D objects on the GSP screen resulting in an obvious change of the classroom atmosphere as compared with that of the previous lesson. The students were engaged in learning by discussing with their peers and busy working on the task in their own computers. One of the school administrators came to observe the lesson. He was very pleased with the students' ability to use GSP to complete the tasks given. Students also found GSP useful and interesting. For instance, one of the students responded that, "I love using GSP very much. Sometimes imagination cannot be really helpful because we tend to make mistakes. But GSP helps to make our imagination work. Love it!" Another student wrote, "I begin to fall in love with geometry ever since I use GSP. It is truly useful for those who can't imagine geometrical constructions. It helps a lot in my learning." One more student said, "GSP is very useful to all students. It is an auspicious start to teach students learning mathematics using GSP.”

Furthermore, the group members managed to administer a pre-test prior to the first teaching of Plans and Elevations during the second LS cycle. The students were asked to draw in full scale the plans and elevations of four different solid objects. Each problem was given 12 marks and therefore 48 was the full mark for the test. The mean score of the pre-test was 13.63 . After the second teaching, a post-test consisting of the equivalent problems were administered to the students on the following day. The mean score of the post-test was 28.42. Thus, the gain score was 14.79 indicating that there was a positive improvement in the students' performance after the second teaching. Figure 6 shows an example of the pre-test questions.

\section{Group C}

Group C consisted of six mathematics teachers. All of them majored in mathematics except for one Malay Language teacher who also taught mathematics. KS was the LS group leader as she had attended a GSP workshop previously. She has some knowledge and skills of using GSP but the other group members were novice users of GSP. Her immediate task was to conduct GSP training sessions for the teachers over several

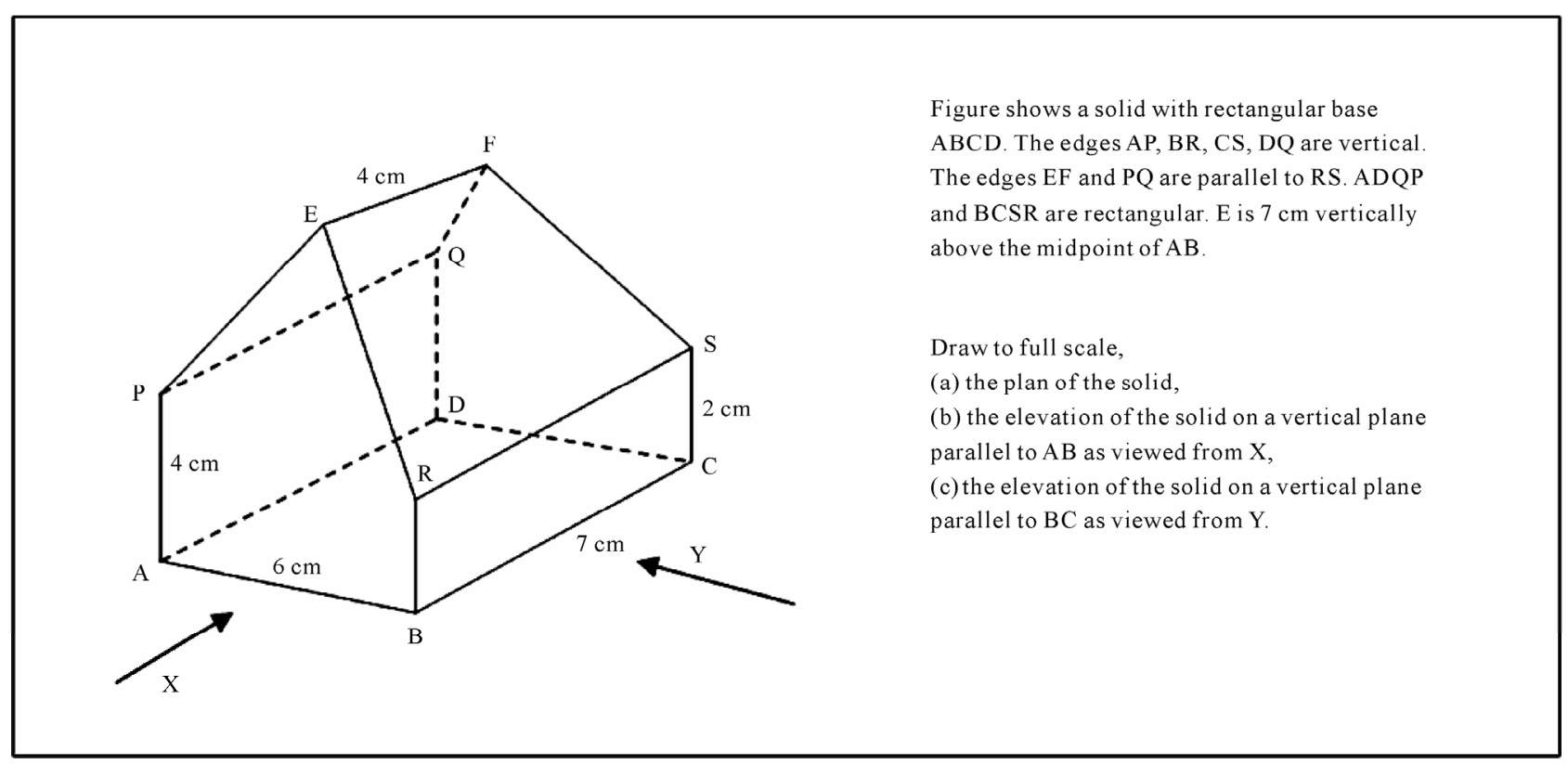

Figure 6.

One of the test questions. Source: Tan (2010: p. 36). 
weekends. Although the training sessions went on well as planned, the teachers were not able to attend the training sessions regularly. It was difficult to record full attendance in any of the sessions because the teachers had other commitments such as administrative and extracurricular duties.

In the first LS cycle, Group C also encountered additional problems such as the group members did not have a good command of English to teach mathematics in English, insufficient skills of using GSP to prepare the lesson materials, over loaded with teaching and administrative work, lack of time to participate fully in this project, lack of confidence and shy to be observed by other group members, as well as having students who were not so competent in English. To overcome the problems, they decided to use ready-made GSP sketches for teaching "Loci in 2-Dimensions" which were prepared by Group A.

A discussion was held in conjunction with the in-house GSP training that was scheduled earlier by the school mathematics committee. The aim of the discussion was to: 1) expose teachers to the ready-made GSP sketches, 2) carry out trial runs of the ready-made GSP sketches to enhance their skills in using GSP to teach the topic, and 3) modify the lesson plan to suit students' ability. A group member volunteered to implement the first teaching. Immediately after her lesson a reflection session was held. Feedbacks from the group members were very encouraging. They found it simple to use the ready-made GSP sketches. Some group members who had never taught the topic before agreed that the ready-made GSP sketches were useful to help students to better understand the topic. In addition, the students found it interesting and easy to follow the lesson (Kalsom Saidin, 2010).

The next day, another group member used the same readymade GSP sketches to conduct the second teaching of the lesson. During the reflection session after the lesson, the group members observed that the students were able to understand the lesson. The teacher also found that it was easier to present the lesson to her students using the ready-made GSP sketches. As a result, all the group members and students were so keen to use GSP so much so that everyone wanted to continue to try using GSP in another topic in the second LS cycle. This time, they chose the topic, "Rotation", because it was a very important topic which can be enhanced by using GSP. They downloaded some ready-made GSP sketches related to the topic from the Internet and used them in their first and second teachings. During the reflection session, all the group members were very pleased and satisfied with the ready-made GSP sketches because they could carry out their teaching easily and smoothly. They observed that their students were also very happy and actively engaged in learning the topic during the lessons. Some reflected that they found learning with GSP enhanced their understanding of the topic and more interesting as well (Kalsom Saidin, 2010).

\section{Constraints and Implications}

Despite the positive feedback from the participating teachers, the LS groups encountered various constraints which challenged both the sustainability of the groups and the encouragement of the innovative use of GSP in the teaching and learning of the geometrical topics in their classes. The main constraints are discussed next (Lim \& Fatimah Saleh, 2010).

\section{Time Constraint}

In LS, teachers need to set time for discussions and observations. They also need time to plan lessons together. In view of the heavy workload that most teachers face today, it is always a great challenge to further stress on their limited time for LS. Very often, they have to sacrifice their weekends and holidays like the case of Group A. Hence, time constraint remains the biggest challenge in our effort to promote LS as a means of encouraging the innovative use of GSP in the teaching and learning of mathematics among secondary school teachers. Consequently, this implies the need to have administrators' support for planning the weekly time table in such a way that the teachers who are involved in LS can have common free periods so that they can discuss, observe each other and practise the skills of using GSP as well.

\section{Commitment}

Teachers might not participate in the LS process wholeheartedly without full commitment. For example, they might give excuses such as "no time", "need to fetch my children" and other family-related reasons to avoid coming for discussions. Some teachers would come late for the meeting but left early. The lack of commitment of some teachers could demoralize the spirit of the LS group members. To gain teachers' full commitment, it is important to make teachers realize and experience the potential benefits of joining the LS group.

\section{Group Leader's Leadership and Personality}

We observed that the degree of success in encouraging the innovative use of GSP in the teaching and learning of mathematics in each LS group varied. We found that constant moral support and encouragement from the group leader is especially important to sustain the group members' commitment. For instance, GSI, the group leader of Group A was very keen in upgrading the professional competency of her group members. She strongly believed that GSP could be an effective tool for teaching mathematics in general and geometry in particular and the innovative use of GSP in mathematics teaching and learning could be encouraged through LS. Hence, she willingly sacrificed her weekends and holidays to her group members to prepare the GSP sketches. By setting a good role model and having fairly good knowledge and skills of using GSP, she was able to give constant and continuous technological, pedagogical and content knowledge support to her colleagues. Moreover, her administrative position as the Senior Teacher of Science and Mathematics in the school had also given her extra authority to call for meetings and access to administrative support as well such as the arrangement of the school time table.

\section{Lack of Hardware and Software Support and Maintenance}

As pointed out by one of the teacher participants, one factor that hindered him from using GSP was the availability and readiness of the hardware and software support and maintenance as well. For instance, as voiced out by GSI that although there were 40 desktop computers in the school lab, only seven of them were in good condition. Hence, she had to borrow laptop computers from all mathematics and science teachers to be used in her lesson. Clearly, the lack of hardware support such 
as not enough computers will discourage the teachers to provide hands-on activities such as using GSP for their students. Sometimes the teachers might encounter the frustrating experience that after spending much time and effort in preparing a lesson using GSP, the computer or the LCD was found not functioning. Clearly this wasted a lot of teaching and learning time and resulted in disappointment and frustration among teachers and students. Hence, it is important for the Ministry of Education and the school administrators to ensure that there is a constant maintenance and update of both software and hardware in schools.

\section{Conclusion}

In this paper, we only managed to share the experiences of three LS groups that aimed to encourage the innovative use of GSP in the teaching and learning of four geometrical topics among secondary school mathematics teachers through LS. We acknowledge the limitation of observing significant changes in the teachers' knowledge and skills of using GSP. Nevertheless, we were very much encouraged by the positive attitude and commitment of the participating teachers as revealed in the teaching observations and interviews. Further, the findings of this study show that LS collaboration can be a potential model of teacher professional development for encouraging the innovative use of GSP in the teaching and learning of mathematics among secondary school teachers.

\section{Acknowledgement}

This project is made possible with funding from the Short Term Grant of Universiti Sains Malaysia, Penang.

\section{References}

Abdullah, N. H. L. (2005). The Effectiveness of using dynamic geometry software on students' achievement in geometry. Unpublished Master's Thesis, Kuala Lumpur, Malaysia: University Malaya.

Bennett, D. (1999). Exploring geometry with The Geometer's Sketchpad. Emeryville, CA: Key Curriculum Press.

Choi, S. S. (1996). Students' learning of geometry using computer software as a tool: Three case studies. Ph.D. Dissertation, Georgia: University of Georgia.

Choi-Koh, S. S. (1999). A student's learning of geometry using the computer. Journal of Educational Research, 92, 301-311. doi:10.1080/00220679909597611

Chi-Koh, \& Sang Sook (2000). The activities based on van Hiele model using computer as a tool. Journal of the Korean Society of Mathematical Education Series D: Research in Mathematical Education, 4, 63-77.

Driskell, S. O. S. (2004). Fourth-grade students' reasoning about properties of two-dimensional shapes. Ph.D. Dissertation, Virginia: University of Virginia.

Elchuck, L. M. (1992). The effects of software type, mathematics achievement, spatial visualization, locus of control, independent time of investigation, and van Hiele level on geometric conjecturing ability. Ph.D Dissertation, University Park, PA: The Pennsylvania State University, URL (last checked on 10 April 2004) http://wwwlib.umi.com/dissertations/fullcit/9226687

Lim, C. S., \& Fatimah Saleh (2010). What can we learn? In C. S. Lim, \& L. K. Kor (Eds.), Innovative use of Geometer's Sketchpad (GSP) through lesson study collaboration (pp. 51-62). Penang: Basic Edu- cational Research Unit, School of Educational Studies, Universiti Sains Malaysia.

Fernandez, C., \& Yoshida, M. (2004). Lesson study: A Japanese approach to improving mathematics teaching and learning. Mahwah, New Jersey: Lawrence Erlbaum Associates.

Finzer, W., \& Jackiw, N. (1998). Dynamic manipulation of mathematical objects. URL (last checked on 2 February 2004) http://wwwlib.keypress.com/sketchpad/talks /s2k/index.htm

Frerking, B. G. (1995). Conjecturing and proof-writing in dynamic geometry. Ph.D. Dissertation, Atlanta, Georgia: Georgia State University, URL (last checked on 10 April 2004)

http://wwwlib.umi.com/ dissertations/fullcit/9507424

Goh, S. I. (2010). The significance of motivator in a lesson study group. In C. S. Lim \& L. K. Kor (Eds.), Innovative use of Geometer's Sketchpad (GSP) through lesson study collaboration (pp. 51-62). Penang: Basic Educational Research Unit, School of Educational Studies, Universiti Sains Malaysia.

Hannafin, R. D., Burruss, J. D., \& Little, C. (2001). Learning with dynamic geometry programs: Perspectives of teachers and learners. The Journal of Educational Research, 94, 132-144. doi:10.1080/00220670109599911

Isoda, M., Stephens, M., Ohara, Y., \& Miyakawa, T. (2007). Japanese lesson study in mathematics: Its impact, diversity and potential for educational improvement. New Jersey: World Scientific. doi:10.1142/9789812707475

July, R. A. (2001). Thinking in three dimensions: Exploring students' geometric thinking and spatial ability with The Geometer's Sketchpad. Ed.D. Dissertation, Miama, Floria: Florida International University.

Kalsom Saidin. (2010). Two in one lesson: "Geolessdy”. In C. S. Lim, \& L. K. Kor (Eds.), Innovative use of Geometer's Sketchpad (GSP) through lesson study collaboration (pp. 32-40). Penang: Basic Educational Research Unit, School of Educational Studies, Universiti Sains Malaysia.

Kasmawati Che Osman (2006). Meninjau penggunaan Geometer Sketch Pad (GSP) di kalangan guru matematik sekolah menengah Pulau Pinang. Unpublished M.Ed Thesis, Universiti Sains Malaysia, Penang.

Lewis, C. (2000). Lesson study: The core of Japanese professional development. Paper presented at the American Educational Research Association meeting, April 2000

Lewis, C., \& Tsuchida, I. (1998). A lesson is like a swiftly flowing river: Research lessons and the improvement of Japanese education. American Educator, 14-17 \& 50-52.

McClintock, E., Jiang, Z., \& July, R. (2002). Students' development of three-dimensional visualization in the Geometer's Sketchpad Environment. Proceedings of the Annual Meeting of the North American Chapter of the International Group for the Psychology of Mathematics Education (ERIC Document Reproduction Service No. ED 471 759)

Olive, J. (2000). Learning geometry intuitively with the aid of a new computer tool: The Geometer's Sketchpad. The Mathematics Educator, 2, 1-5. URL (last checked on 11 August 2003) http://jwilson.coe.uga.edu/DEPT/IME/Issues/v02n1/5olive.html

Shimahara, N. K. (1998). The Japanese model of professional development: Teaching as craft. Teaching \& Teacher Education, 14, 451462. doi:10.1016/S0742-051X(97)00055-3

Stigler, J. W., \& Hiebert, J. (1997). Understanding and improving classroom mathematics instruction: An overview of the TIMSS video study. Phi Delta Kappan, 79, 14-21.

Stigler, J. W., \& Hiebert, J. (1999). The teaching gap: Best ideas from the world's teachers for improving education in the classroom. NewYork: The Free Press.

Tan, K. A. (2010). In search of best practices. In C. S. Lim \& L. K. Kor (Eds.), Innovative use of Geometer's Sketchpad (GSP) through lesson study collaboration (pp. 41-50). Penang: Basic Educational Research Unit, School of Educational Studies, Universiti Sains Malaysia.

Teoh, B. T., \& Fong, S. F. (2005). The effects of geometer's sketchpad 
and graphic calculator in the Malaysian mathematics classroom. Malaysian Online Journal of Instructional Technology, 2, 82-96.

Thompson, E. (2006). Euclid, the van Hiele levels, and the Geometer's Sketchpad. (MST thesis, Florita Atlantic University, 2006). Masters Abstracts International, 44, 2529. URL (last checked on 2 February
2007) http://wwwlib.umi.com/ dissertations/fullcit/1435803

Yoshida, M. (1999). Lesson study (jugyokenkyu) in elementary school mathematics in Japan: A case study. Paper presented at the American Educational Research Association (1999 Annual Meeting), Montreal, Canada. 